\title{
Laboreal
}

Volume $8 \mathrm{~N}^{\circ} 1$ | 2012

Género, Atividades e Saúde

\section{Relações sociais de gênero e divisão sexual do trabalho : desafios para a compreensão do uso do tempo no trabalho docente}

Las relaciones sociales de género y la división sexual del trabajo :desafíos para la comprensión del uso del tiempo trabajo docente

Rapports sociaux de genre et division sexuelle du travail :défis pour la compréhension de l'utilisation du temps dans le travail enseignant Social relations of gender and sexual division of labor :challenges to understanding the use of time in teaching

\section{Carolina Faria Alvarenga e Cláudia Pereira Vianna}

\section{OpenEdition}

Journals

\section{Edição electrónica}

URL: http://journals.openedition.org/laboreal/6934

DOI: 10.4000/laboreal.6934

ISSN: 1646-5237

Editora

Universidade do Porto

Refêrencia eletrónica

Carolina Faria Alvarenga e Cláudia Pereira Vianna, « Relações sociais de gênero e divisão sexual do trabalho : desafios para a compreensão do uso do tempo no trabalho docente », Laboreal [Online], Volume $8 \mathrm{~N}^{0} 1$ | 2012, posto online no dia 01 julho 2012, consultado o 08 outubro 2019. URL : http:// journals.openedition.org/laboreal/6934; DOI : 10.4000/laboreal.6934

Este documento foi criado de forma automática no dia 8 outubro 2019

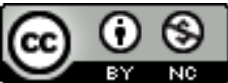

Laboreal está licenciado com uma Licença Creative Commons - Atribuição-NãoComercial 4.0 Internacional. 


\section{Relações sociais de gênero e divisão sexual do trabalho : desafios para a compreensão do uso do tempo no trabalho docente}

Las relaciones sociales de género y la división sexual del trabajo :desafíos para la comprensión del uso del tiempo trabajo docente

Rapports sociaux de genre et division sexuelle du travail :défis pour la compréhension de l'utilisation du temps dans le travail enseignant Social relations of gender and sexual division of labor :challenges to understanding the use of time in teaching

Carolina Faria Alvarenga e Cláudia Pereira Vianna

\section{NOTA DO EDITOR}

Manuscrito recebido em : Fevereiro/2012

Aceite após peritagem : Abril/2012

\section{Introdução}

1 O campo de estudos de gênero inspira inúmeras pesquisas em áreas diversas do conhecimento. Durante muito tempo, foi tido como sinônimo de investigações sobre a mulher em diferentes culturas e sociedades. Partiu da constatação da subordinação e da posição desigual das mulheres em relação aos homens e inspirou inúmeras pesquisas. A elaboração do conceito recebeu e ainda recebe forte influência de diferentes campos como Sociologia, Linguística, Psicanálise, Psicologia, História e Antropologia, 
responsáveis por demonstrar a variabilidade cultural dos comportamentos, aquisições e habilidades consideradas femininas e masculinas.

2 Hoje não é tão simples pensar em uma área de conhecimento cuja categoria de análise seja a mulher. A defesa do uso do conceito passou a adquirir caráter relacional e a englobar as relações sociais entre homens e mulheres, entre mulheres e mulheres, entre homens e homens, com a inclusão da crítica à heteronormatividade (Butler, 1993 ; Scott, 1994, 1995).

3 Ao conceito de gênero cabe a tarefa de problematizar os significados do que é ser mulher e homem nos distintos contextos históricos. Ou seja, é útil para questionar o fato de que em nossa sociedade as explicações sobre as diferenças entre homens e mulheres são fortemente qualificadas pelo sexo, com evidentes conotações biológicas. Tais explicações possuem forte intenção de produzir hierarquias que sustentem relações desiguais e de dominação no âmbito específico das relações sociais de gênero e na sua articulação com classe, raça, etnia e geração.

4 O mesmo processo se dá com o conceito de divisão sexual do trabalho. Até o século XIX, apesar de vozes dissidentes, caracterizava-se pela incapacidade de abarcar a construção histórica da mulher trabalhadora. Entretanto, essa construção está relacionada à configuração do conceito de divisão sexual do trabalho e possibilita examinar como essa divisão cria uma força de trabalho feminina, vista como mão de obra barata para certos tipos de afazeres, e como produz relações desiguais, hierarquizadas e assimétricas de exploração e opressão.

5 É nesse sentido que os conceitos de gênero e divisão sexual do trabalho tornam-se indissociáveis. Mas a divisão sexual do trabalho é apenas um aspecto das relações de gênero. Gênero é a categoria de análise que permite desmontar arquétipos, como salienta Helena Hirata (1998), do que é ser trabalhador e trabalhadora em nossa sociedade.

6 É a crítica de gênero que comporta, por exemplo, a ampliação do conceito de trabalho para além do trabalho assalariado e contempla as atividades desenvolvidas por mulheres como o trabalho doméstico, a gestão da casa, o trabalho não remunerado ou inserido nas mudanças que acompanham a especialização flexível.

7 No Brasil - com característica interdisciplinar e apoio em um quadro conceitual estável e consistente - o conceito de gênero tem sido amplamente incorporado às análises sobre a divisão sexual do trabalho. Nessa trajetória de produção foi muito fértil o diálogo com produções feministas voltadas para a desconstrução da dualidade entre sexo (naturalmente adquirido) e gênero (culturalmente construído), mostrando-se que o sexo não é natural, mas também discursivo e cultural como o gênero.

8 Esse é o caso da ampla investigação sobre as construções do sexo e do corpo sexuado, realizada por Anne Fausto-Sterling (2000), professora de biologia e Women's Studies, do Departamento de Biologia Molecular e Celular e Bioquímica da Universidade Brow. A autora põe em xeque inúmeras pesquisas que atestam a existência de uma anatomia cerebral específica para cada sexo. Daí viria o fundamento para conferir às mulheres e à caracterização específica de seu cérebro a intuição, a falta de aptidão para as ciências exatas, a ampla habilidade verbal e o uso simultâneo de ambos os hemisférios cerebrais. Aos homens, em geral, seria, então, atribuído melhor desempenho espaço-visual, matemático e científico. 
9 Ao articular biologia, medicina e ciências sociais, Fausto-Sterling (2000) questiona o uso das relações sociais feito pelas pesquisas da área biológica para estruturar seu conhecimento sobre a natureza e, ao mesmo tempo, reduzir o mundo social a ela. A autora defende o caráter social do conhecimento biológico sobre a sexualidade humana e animal, revelando como as diferenças culturais se transformam em distinções corporais na produção de conhecimento na área da biologia. Em outras palavras, tais estudos passam da discussão das diferenças externas e do ambiente social para as diferenças internas, do organismo biológico e seus efeitos sobre o que se entende por masculinidade e feminilidade.

10 Esse diálogo descortina caminhos para uma crítica mais incisiva às características tidas pela tradição como naturalmente masculinas ou femininas e às afirmações biológicas sobre corpos, comportamentos e habilidades de mulheres e homens, destacando o caráter socialmente construído da segmentação do mercado de trabalho para as mulheres; da desigualdade presente na abordagem da qualificação feminina; da necessidade de ampliação do conceito de trabalho doméstico e da contribuição do conceito de gênero para a análise do uso sexuado do tempo no trabalho docente, para entrar no campo específico da educação no cruzamento com a divisão sexual do trabalho.

11 A feminização da categoria docente é um fenômeno internacional. No Brasil, inúmeras pesquisas destacam a composição sexual predominantemente feminina da categoria $e$ sua relação com um mercado de trabalho para mulheres brancas de classes médias, com o caráter patriarcal de nossa sociedade e com as discriminações de gênero em geral (Louro, 1989 ; Costa, 1995 ; Carvalho, 1999). Mais recentemente, a produção na área da história da educação vem dando um amplo destaque à feminização do magistério (Vidal, 2006). Ressalta-se que, para além da presença maciça de mulheres, as características consideradas femininas também envolvem todo esse "universo feminino". Uma profissão que se feminizou também em decorrência das alterações econômicas, demográficas, sociais, culturais e políticas a partir da virada do século XX (Vianna, 2002). Álvaro Hypolito (1997) acrescenta que essa feminização foi também parte integrante do processo de expansão do ensino, do aumento de vagas nas escolas primárias e normais e dos significados de gênero construídos e modificados historicamente. Uma profissão compatível com o ideal de feminilidade (Scott, 1994).

Podemos dizer que, atualmente, a profissão ainda carrega os elementos tradicionalmente associados às desigualdades às quais a condição feminina é submetida, como a desvalorização, os baixos salários, a concepção de uma atividade temporária, transitória, em tempo parcial e com um salário complementar? As novas configurações sociais, econômicas, políticas, demográficas do final do século XX e início do século XXI e a presença cada vez maior de homens no magistério, possibilitaram a resignificação do trabalho docente? Há uma sobrecarga de trabalho que atinge os professores e as professoras da mesma forma? O uso dos tempos de trabalho docente são sexuados?

13 Portanto, esse é o foco privilegiado por este artigo : a compreensão das hierarquias e tensões relacionadas aos significados de gênero nas jornadas e nos ritmos de trabalho no cotidiano de professoras e professores. 


\section{Relações de gênero e divisão sexual do trabalho : desafios para a compreensão dos tempos de trabalho}

14 Para a análise das jornadas e ritmos do trabalho docente, é importante a problematização das relações sociais, que não são neutras. Necessariamente conflituosas, remetem a relações de poder e, certamente, uma de suas dimensões é a relação de gênero.

15 O conceito de gênero já é bastante utilizado em diversos países e em variadas áreas do conhecimento, mas sua força vem dos Estados Unidos e da Inglaterra. Nasceu com o movimento feminista, em uma denúncia contra o poder e a dominação masculinos. Por serem diversos o entendimento e a utilização do conceito, recorremos a Joan Scott $(1995,1998)$, historiadora e feminista norte-americana, que o define como "o discurso da diferença dos sexos", ou "a organização social dos sexos" e reforça que "não se refere apenas às ideias, mas também às instituições, às estruturas, às práticas cotidianas, como também aos rituais e a tudo o que constitui as relações sociais" (Scott, 1998, p. 115).

16 Mesmo sem mencionar o gênero como conceito, Danièle Kergoat (2000) ressalta que relações sociais de sexo e divisão sexual do trabalho são indissociáveis e formam um sistema epistemológico. Para ela, as diferenças entre as práticas dos homens e as das mulheres são construções sociais e não se originam de causas biológicas. Trata-se de uma construção social e expressa relações sociais de poder, de dominação e de hierarquia.

17 Joan Scott não considera um problema o uso de "gênero" ou "relações sociais de sexo". Ao contrário, ela reforça que isso é menos importante do que colocar a questão em termos históricos. Devemos pensar como as relações entre os sexos foram construídas em dado momento histórico e político. Não há uma essência das mulheres - e dos homens, acrescentaríamos ; tampouco há uma subjetividade feminina ligada ao corpo, à natureza, à reprodução, à maternidade ; ou ligada à cultura, à produção, à virilidade, para os homens. Ao contrário, há subjetividades - femininas e masculinas - criadas em determinado contexto histórico, cultural e político. É preciso, portanto, historicizar o modo pelo qual essas subjetividades foram cunhadas ao longo do tempo (Scott, 1998).

Por concordarmos com o ponto de vista defendido por essas autoras, recusamos qualquer tentativa de explicação exclusivamente biológica sobre as diferenças entre homens e mulheres, em suas vivências, concepções, atitudes, comportamentos e sentimentos. Essa é a nossa premissa para refletirmos sobre a intersecção entre gênero e divisão sexual do trabalho, em um primeiro momento, para depois analisarmos o trabalho docente propriamente dito.

19 As relações sociais de sexo, como todas as relações sociais, têm uma base material e exprimem-se por meio da divisão social e sexual do trabalho, caracterizada, segundo Kergoat (2000), pela separação entre a esfera reprodutiva, destinada às mulheres, e a esfera produtiva, destinada aos homens, sendo esta associada às funções mais valorizadas socialmente, como as políticas, religiosas, militares, etc.

20 Portanto, esta forma de divisão social organiza-se, segundo Kergoat (2000), sob dois princípios: o princípio da separação ("trabalhos de homens" e "trabalhos de mulheres") e o da hierarquização ("trabalhos de homens" valem mais que os "trabalhos de mulheres"). 0 processo de legitimação desses princípios baseia-se em uma ideologia 
essencialista que reduz as práticas sociais a papeis sexuais e as coloca como destino natural de cada sexo.

21 No entanto, a teorização em termos da divisão sexual do trabalho possibilita questionar esse suposto destino e afirmar o caráter social das práticas sexuais. Estas, não são, portanto, dados rígidos e imutáveis, ou seja, ainda que os princípios sejam os mesmos, suas modalidades - concepção de trabalho reprodutivo, lugar das mulheres no mercado de trabalho, etc. - variam no tempo e no espaço. Um exemplo dessa variabilidade é quando uma mesma tarefa, especificamente feminina em uma sociedade, pode ser considerada tipicamente masculina em outra (Kergoat, 2000).

Os resultados de pesquisas que, nas últimas décadas, debruçaram-se sobre este debate permitem a compreensão da trajetória percorrida entre a formulação de um conceito estrutural de divisão sexual do trabalho e a sua reformulação como relação social, simbólica e histórica. Na primeira linha, os estudos afirmam que a divisão sexual do trabalho insere-se na divisão sexual da sociedade, na construção do que é considerado como masculino ou feminino, muitas vezes apresentado como natural e biológico. $\mathrm{Na}$ segunda, entende-se que a divisão sexual do trabalho "não cria a subordinação e a desigualdade das mulheres no mercado de trabalho, mas recria uma subordinação que existe também nas outras esferas do social" (Souza Lobo, 1991, p. 61).

23 Assim, os estudos da Sociologia do Trabalho, sob a ótica das relações sociais entre os sexos e das relações de gênero, permitem ressignificar o uso e os sentidos da divisão sexual e dos tempos do trabalho de homens e mulheres. Há também, nessa concepção, uma divisão sexual do tempo no trabalho e fora dele.

O conceito de tempo representa um alto nível de generalização e síntese, uma vez que relaciona acontecimentos que ocorrem no fluxo ininterrupto do devir e não se deixam justapor, nem comparar diretamente. Pressupõe um "riquíssimo patrimônio social de saber no que concerne aos métodos de mensuração das sequências temporais e às regularidades que elas apresentam" (Elias, 1998, p. 35).

Podemos dizer que, nas sociedades contemporâneas, o tempo tornou-se não apenas um instrumento de orientação indispensável para uma variedade de tarefas, mas também um instrumento de regulação da conduta e da sensibilidade humana.

Trazendo essa discussão para as sociedades complexas, nas quais as tecnologias estão cada vez mais desenvolvidas, Alberto Melucci (2004) afirma que hoje o tempo é uma experiência múltipla e descontínua. Velocidade e lentidão, movimento e repouso, alternância e ritmo combinam-se em nossas vidas. É um tempo cada vez mais fragmentado, no qual nossos desejos, nossos sonhos, nossos afetos e emoções estão distantes das cadências e das regras sociais, reguladas por uma máquina uniforme, mensurável e previsível.

Há também uma multiplicidade de âmbitos na vida, na experiência e nas relações dos sujeitos, nos quais a "mudança é veloz e o campo das possibilidades é infinitamente mais amplo do que aquele que podemos efetivamente experimentar com nossa capacidade de ação" (Melucci, 2004, p. 33). Essas características acarretam na vida dos sujeitos uma permanente condição de incerteza que, por sua vez, faz com que o tempo dedicado para realização de escolhas e decisões seja constante.

28 A análise do uso do tempo também implica o entendimento da cotidianidade e dos contornos rítmico-temporais da vida no dia-a-dia. Anthony Giddens (1989) assinala que a rotina é um conjunto de práticas recorrentes, sobre as quais os sujeitos sociais tecem 
considerações, interpretações e entendimentos, mediante a reflexividade de que são capazes, a qual se expressa na discursividade e em sua consciência prática. No entanto, apesar de continuidades e permanências, as práticas sociais são constantemente examinadas e reelaboradas a partir de descobertas sucessivas que passam a informá-las.

Inês Teixeira (1998), em constante diálogo com Henri Lefebvre e Catherine Régulier, analisa três aspectos que envolvem a rítmica do tempo cotidiano. $O$ primeiro deles refere-se ao tempo social como produto da vida coletiva, marcado pela organização socioeconômica da produção, do consumo, da circulação e da habitação. 0 segundo aspecto refere-se à organização rítmica do tempo cotidiano, ou seja, os ritmos da vida dos sujeitos são, simultaneamente, interiores e sociais. O terceiro envolve a fragmentação dos tempos, que determina a separação dos tempos de trabalho dos tempos destinados ao lazer, ao ócio e a tantas outras temporalidades da vida dos sujeitos.

No entanto, é importante ter clareza de que todos os fatores descritos acerca do tempo, como a fragmentação e a multiplicidade temporal, os marcadores do tempo que impõem durações e ritmos da vida social e a cotidianidade, são distintos muitas vezes para homens e mulheres. As implicações decorrentes das configurações temporais têm também uma dimensão de gênero.

31 O economista Cláudio Dedecca (2004) defende que, para discutir tempo e trabalho nas sociedades capitalistas, a tensão entre o tempo para a reprodução econômica e o tempo para a reprodução social deve ser sempre considerada. Ele afirma que a dimensão de gênero é imprescindível para a análise do uso do tempo no capitalismo. De um lado, o tempo para reprodução econômica refere-se ao trabalho remunerado e ao tempo gasto com deslocamentos para sua realização. De outro, o tempo para a reprodução familiar e social envolve as atividades de organização domiciliar, de lazer e de sono.

32 Ao contrário de Dedecca, Joffre Dumazedier (1973) não considera que o lazer esteja incluído no tempo de trabalho para a reprodução social. Para ele, lazer é entendido como:

um conjunto de ocupações às quais o indivíduo pode entregar-se de livre vontade, seja para repousar, seja para divertir-se, recrear-se e entreter-se ou, ainda, para desenvolver sua informação ou formação desinteressada, sua participação social voluntária ou sua livre capacidade criadora, após livrar-se ou desembaraçar-se das obrigações profissionais, familiares e sociais (Dumazedier, 1973, p. 34).

Porém, não seria bastante tênue a separação do que é considerada uma atividade de lazer de uma ocupação que envolve familiares, em especial, filhos(as) pequenos(as) ? Não estaríamos reforçando uma dicotomia entre obrigações e lazer? Seriam as obrigações profissionais, familiares e sociais sinônimo de tempos destinados à reprodução, seja ela econômica ou social ?

Até a década de 1970, os instrumentos de regulação e padronização da jornada de trabalho visavam a separação entre o tempo para a reprodução econômica e para a reprodução social, permitindo maior compatibilidade entre o trabalho e a vida familiar. No entanto, a jornada padronizada de trabalho vem sendo gradativamente substituída por jornadas em regime excepcional de trabalho (Dedecca, 2004).

Recorrentes nos finais de semana, à noite ou por turnos, as jornadas de trabalho em regimes excepcionais eram restritas somente aos hospitais e às empresas de 
distribuição elétrica, por necessidade social, e nas siderúrgicas e petroquímicas, por imposição técnica. No entanto, a partir dos anos de 1980, com o crescimento do desemprego, a flexibilização das jornadas tornou-se intensamente difundida. Assim, a sincronização no uso do tempo no interior das famílias tornou-se mais difícil e o tempo social passou a ser ainda mais subordinado ao tempo econômico, com uma redução do tempo livre na vida das pessoas (Dedecca, 2004). Sem deixar de ressaltar que ambos carregam traços distintos da divisão do trabalho para homens e mulheres e dos paradoxos de gênero dela decorrentes.

A partir dos anos de 1970, o processo de reestruturação produtiva provocou um intensivo crescimento da feminização do mundo do trabalho. Nessa época, $40 \%$ da força de trabalho dos países capitalistas ocidentais já era composta por mulheres (Hirata, 2002; Dedecca, 2004; Nogueira, 2004; Antunes, 2006). No Brasil, as trabalhadoras, antes solteiras, jovens e sem filhos(as), passaram a ser mais velhas, casadas e com filhos(as) (Bruschini, 2000).

No entanto, em decorrência da flexibilização das jornadas, da informalização e do regime de trabalho em tempo parcial e temporário, muitas consequências no mundo do trabalho surgiram, principalmente para a mão-de-obra feminina.

Nos anos de 1990, os efeitos da mundialização do capital foram diferentes para os empregos femininos e masculinos. Apesar de a inserção das novas tecnologias suprimir tanto a mão-de-obra não qualificada masculina como a feminina, coube aos homens a ocupação das novas funções qualificadas, enquanto as mulheres, se não expulsas do mercado, continuaram a ocupar os postos de trabalho periféricos e secundários. Mesmo com o crescimento da ocupação feminina, tanto no espaço formal quanto no informal, as mulheres permaneceram praticamente ausentes dos postos técnicos e longe dos equipamentos caros e competitivos (Hirata, 2002 ; Nogueira, 2004).

39 As séries históricas constantes do banco de dados sobre trabalho das mulheres, organizado pela Fundação Carlos Chagas [1], também mostram a grande variedade das condições de inserção das mulheres no mercado de trabalho, problematizando situações de remuneração, estabilidade e precariedade extremamente diferenciadas.

As informações sistematizadas pelo referido banco de dados evidenciam que a ampliação do contingente feminino no mercado de trabalho brasileiro desde os anos 1970 é resultante de uma série de fatores. Entre eles, encontramos as necessidades econômicas da população e as oportunidades oferecidas pelo mercado, mas também transformações demográficas, culturais, sociais e políticas. $\mathrm{O}$ casamento mais tardio, a queda da fecundidade, a redução do número de filhos(as) e a diminuição dos óbitos maternos durante o parto - em 1960, registravam-se 150 óbitos maternos no Estado de São Paulo enquanto que, em 1995, esse número foi reduzido para 45 - e a participação feminina na política contribuíram para esse processo. As modificações culturais quanto ao papel das mulheres; as alterações na composição familiar diante do significativo índice de separações e de famílias chefiadas por mulheres. A expansão da escolaridade de homens e mulheres, mas especialmente dessas últimas, somados aos fatores acima elencados, introduziram mudanças significativas na vida das mulheres nas últimas décadas, com destaque para a ampla inserção no trabalho formal e informal.

Podemos também localizar nos últimos quinze anos uma pequena parcela de mulheres escolarizadas com novas oportunidades de trabalho em ocupações de nível superior de prestígio como medicina, arquitetura, direito e engenharia, searas até então consideradas eminentemente masculinas. Entre os fatores que contribuíram para a 
inserção feminina em ocupações de prestígio, encontramos a "intensa transformação cultural, a partir dos anos $60 \mathrm{e}$, sobretudo, nos 70 (...) que impulsionou as mulheres para as universidades, em busca de um projeto de vida profissional" assim como "a racionalização e as transformações pelas quais passaram essas profissões" (Bruschini \& Lombardi, 1999, p. 22).

Por outro lado, conforme as investigações destacadas por essa série histórica, a ampliação da grande maioria da População Economicamente Ativa (PEA) feminina, aliada ao aumento da escolarização das mulheres, garante somente a permanência em um posto de trabalho ligado, na maior parte dos casos, ao setor de serviços da economia, considerado tipicamente feminino, informal, desprotegido, com precárias condições de trabalho, baixos salários, instabilidade e pouca possibilidade de ascensão (Abramo \& Abreu, 1998; Bruschini, 2000 ; Posthuma, 1998). Mais de $70 \%$ das mulheres ativas no mercado de trabalho continuam empregadas em profissões consideradas femininas, como é o caso das fonoaudiólogas, nutricionistas, biblioteconomistas, cozinheiras e professoras.

Identificamos um processo de exclusão das mulheres e de masculinização da força de trabalho, assim como situações de "inserção excluída". Essa expressão é cunhada por Anne Posthuma (1998) para anunciar a segregação horizontal (em alguns setores econômicos como o terciário e as indústrias mais tradicionais) e vertical (em postos de menor nível hierárquico e com baixos salários) das mulheres e sua inserção em funções menos qualificadas, com condições precárias e baixa possibilidade de mobilidade ocupacional.

Dessa forma, podemos afirmar que a expansão da entrada das mulheres no mercado de trabalho esteve e está ligada à "inserção excluída". Ou seja, as oportunidades de emprego para as mulheres são contraditórias: ganham os mais baixos salários e encontram-se em trabalhos precários e informais.

Quanto aos salários, destaca-se o declínio dos rendimentos médios das mulheres. Na Região Metropolitana de São Paulo, a renda média dos homens, em 1997, era de 4,6 Salários Mínimos, enquanto que a das mulheres era de 2,6 Salários Mínimos. De acordo com o Instituto Brasileiro de Geografia e Estatística (Brasil, IBGE, 2011), entre 2003 e 2007, a renda média do(a) trabalhador(a) brasileiro(a) aumentou $14,3 \%$ nas seis principais regiões metropolitanas do país. Houve alta em todas as regiões pesquisadas pelo IBGE, mas ainda assim o rendimento médio das mulheres continua sendo menor que o dos homens. A renda média delas ficou em torno de $72,3 \%$ do rendimento recebido pelos homens, situação que não mudou significativamente desde 2003, quando esse percentual era de 70,8\%. Discrepância ainda maior foi observada entre os rendimentos dos trabalhadores do grupo formado por pretos(as) e pardos(as) e os(as) de cor branca.

46 Assim, encontramos um quadro extremamente complexo, no qual predomina a inserção feminina nos setores de serviços, comércio e indústria, no trabalho formal e informal, numa grande diversidade de carreiras, que abrange desde o ingresso de algumas mulheres em ocupações de prestígio até a manutenção de um grande número de mulheres em condições menos favoráveis de trabalho.

Além disso, as pesquisas indicam que são as mulheres aquelas que ocupam a maior parte dos postos de trabalho em tempo parcial e, mesmo assim, elas teriam um tempo 
de trabalho total maior que o dos homens, por serem responsáveis pelo trabalho doméstico (Dedecca, 2004 ; Venturi, Recamán \& Oliveira, 2004).

É a partir desse contexto que propomos, nesse artigo, problematizarmos as jornadas e os ritmos de trabalho no cotidiano de professoras e professores.

\section{Jornadas e ritmos da docência : para além das dicotomias entre os sexos}

Inês Teixeira (1998, p. 2002), ao analisar o uso dos tempos de professores e professoras, propõe que é preciso "discutir aspectos como o desempenho de tarefas concomitantes, o lazer interrompido, a administração de relações e dinâmica familiar que dão qualidade aos tempos [das professoras], tornando seus ritmos mais intensos". A autora acrescenta que, diferentemente das mulheres de outras categorias profissionais, as professoras possuem tripla jornada, e não dupla, uma vez que, além do trabalho na escola, há os serviços escolares realizados em casa e o trabalho doméstico. Mesmo quando não executam as atividades domésticas, ou seja, quando recebem ajuda de terceiros - como as empregadas domésticas -, elas são as responsáveis pela administração desses serviços (Teixeira, 1998).

$\mathrm{E}$ os docentes, homens ou mulheres, que lecionam em três escolas diferentes, despendem bastante tempo no deslocamento entre escolas e residência e têm parte de seus finais de semana ocupados com os serviços escolares? Não teriam também o tempo de lazer interrompido, tarefas concomitantes, mesmo não tendo a responsabilidade pela execução ou administração do trabalho doméstico ? Estariam esses profissionais tão aturdidos quanto aqueles que realizam também o trabalho doméstico?

51 A profissão docente é caracterizada pelo trabalho em turnos. Considerando, portanto, que grande número de docentes trabalha em duas ou três escolas, podemos dizer que essa configuração de trabalho em tempo parcial permanece ainda hoje? Estariam as professoras nas mesmas condições ? E os professores teriam, assim como os homens em geral, maior tempo de trabalho econômico?

Como diferenciar e também agrupar as dimensões que caracterizam o trabalho docente para além dos sexos? Se este é fortemente caracterizado pela grande intensificação, pelo acúmulo de jornadas e de instituições, ou até mesmo pelo acréscimo do exercício de outra função, fora da docência, como captar as tensões que o definem ? Podemos afirmar que as professoras possuem grandes responsabilidades pelo sustento da casa e os professores incluem serviços domésticos em suas atividades diárias? A tarefa que se mostrou urgente e necessária foi ultrapassar as dicotomias entre os sexos, sem perder as tensões entre público e privado e entre trabalho econômico essencialmente masculino e trabalho feminino voltado para a reprodução social.

\section{Sobre a investigação realizada e o método de análise}

Tendo em vista o objetivo central de compreender como eram vividos e sentidos os diversos tempos cotidianos de professoras e professores, a partir da complexidade de suas vidas, das relações conflituosas entre as diversas marcas que compõem suas 
identidades, e das relações de poder que perpassam a sua construção, considerou-se a possibilidade de realização de uma investigação qualitativa.

A pesquisa empírica (Alvarenga, 2008) foi desenvolvida com professoras e professores de Ensino Fundamental II de uma escola municipal de São Paulo entre 2006 e 2007. Como a instituição escolar é um dos pontos que une as(os) docentes, foi necessário escolher uma escola para realizar a investigação: um Centro Educacional Unificado (CEU) localizado na zona sul da cidade de São Paulo/Brasil, que atende crianças e adolescentes, nos períodos da manhã e da tarde, e jovens e adultos, no período noturno, todos(as) de classe baixa, moradores(as) da região.

Os CEUs integram a Rede Municipal de Ensino de São Paulo e, no geral, seu conjunto arquitetônico é desenhado por prédios que abrigam : 1) equipamentos da Secretaria Municipal da Educação: creche, educação infantil e ensino fundamental; 2) equipamentos da Secretaria Municipal da Cultura : biblioteca pública, teatro municipal e casa de cultura (ateliês de artes plásticas, estúdios de música, rádio e televisão, salão de dança) ; 3) equipamentos da Secretaria Municipal de Esportes e Lazer : ginásio de esportes (quadra poliesportiva coberta e salão de ginástica), balneário municipal (conjunto aquático de três piscinas e solário) e parque de esportes (quadras poliesportivas, pistas de skate, campos de futebol) ; 4) um equipamento do governo de inclusão digital : telecentro (computadores com acesso à Internet) ; 5) padaria-escola ; e 6) sala do Conselho Gestor (gestão intersecretarial e participativa com a comunidade).

A pesquisa de campo teve início em 2006 e dentre os três níveis da Educação Básica, foi privilegiado o Ensino Fundamental II, considerando que teria um número significativo de docentes de ambos os sexos. Ainda assim, confirmando as pesquisas educacionais sobre a predominância feminina no magistério, havia, em 2006, na escola pesquisada, em um total de 19 docentes, somente quatro do sexo masculino.

Seguindo as observações de Michel Thiollent (1987, p. 22) para quem os instrumentos na pesquisa sociológica são "dispositivos de obtenção de informação, cujas qualidades, limitações e distorções devem ser metodologicamente controladas", a investigação abrangeu questionários, diários de uso do tempo e entrevistas.

Foram aplicados 19 questionários, com o retorno de 16, cujo objetivo foi obter maior abrangência de informações na coleta de dados, possibilitando o conhecimento do cotidiano de um número maior de docentes e a construção de uma breve caracterização do grupo. Apesar desse recurso ser um instrumento que permite maior representatividade dos sujeitos da pesquisa, apresenta algumas limitações, segundo Guy Michelat (1987), uma vez que as respostas dos(as) entrevistados(as) ficam limitadas às informações solicitadas pelo(a) pesquisador(a). Maria Isaura Pereira de Queiroz (1985) acrescenta que o questionário, mesmo contendo questões abertas, é um instrumento que possibilita menor riqueza de detalhes por parte dos(as) informantes, mas, por outro lado, permite atender algumas necessidades de informação.

Entendendo as limitações do uso dos questionários, mas reconhecendo que sua utilização possibilitaria o conhecimento de um maior número de docentes, recorremos também a outros dois instrumentos de coleta de dados, um deles, o diário de uso do tempo, no qual sete docentes (quatro homens e três mulheres) registraram todas as suas atividades, com o horário de início e de fim - até mesmo o tempo gasto com deslocamentos -, considerando dez dias corridos, incluindo o final de semana. 
60 A utilização dos diários foi inspirada em uma pesquisa realizada por Jane Carvalho (2001). Com o intuito de conhecer os usos do tempo com crianças sob o enfoque de gênero e classe social, a autora utilizou o diário desenvolvido pela Universidade de Michigan. No entanto, ao invés de uma abordagem indireta, na qual o(a) responsável pela criança preenche o diário, a autora priorizou a participação direta das crianças.

61 A terceira e principal opção para a coleta dos dados foi o uso de entrevista semiestruturada realizada com quatro dos(as) sete docentes que se dispuseram a preencher os diários. Caracterizada por Thiollent (1987) e Michelat (1987) como entrevista nãodiretiva, esse instrumento permite um aprofundamento maior dos dados coletados, além de possibilitar uma relação entre o grau de liberdade deixado e o nível de profundidade das informações que ele ou ela pode fornecer. Ademais, melhor do que outros métodos, a entrevista consegue captar aspectos de ordem sócio-afetiva dos sujeitos, como é o caso do modo como professoras e professores sentem e significam o uso de seu tempo.

Queiroz (1985) ressalta, porém, que, apesar de certa liberdade na condução da fala pelo(a) informante, o fato da pesquisadora ainda controlar o que vai ser discutido faz com que exista uma relação de dominação, ainda que camuflada. Considera que, pelo fato de as perguntas estarem dentro dos interesses da pesquisa, há um desprezo sobre aquilo que foi narrado e que aparentemente pode não fazer sentido com a discussão. Pierre Bourdieu (1997) também nos alerta para os efeitos que podemos produzir nos(as) entrevistados(as) a partir de uma espécie de intrusão arbitrária que está no princípio da troca. Concordando, em parte, com a crítica feita pelos autores em questão, consideramos que pode haver uma relação de dominação entre pesquisadora e pesquisados(as), mas há meios de tentar reduzir ao máximo a violência simbólica que pode ser exercida em uma situação de entrevista. Uma das maneiras de diminuir essa intrusão é ter um conhecimento prévio dos entrevistados(as), o que "permite improvisar continuamente as perguntas pertinentes, verdadeiras hipóteses que se apoiam numa representação intuitiva e provisória da fórmula geradora própria ao pesquisado para provocá-lo a se revelar mais completamente" (Bourdieu, 1997, p. 700).

Garantidas as condições para reduzir a violência simbólica na relação de pesquisa, Bourdieu afirma que a entrevista pode ser considerada uma oportunidade de construir e manifestar seu próprio ponto de vista sobre si mesmo e sobre o mundo. Seria um momento de auto-análise provocada e acompanhada, no qual experiências e reflexões há muito reprimidas poderiam vir à tona.

64 Segundo Michel Le Ven e colaboradoras (1997), os(as) entrevistados(as), quando percebem seu projeto de vida, passam de objetos para sujeitos da pesquisa. Além disso, o modo de vida do entrevistado(a) também produz um efeito em nós, entrevistadoras(es), pois passamos a refletir sobre nossas próprias vidas, a partir do depoimento do outro. Assim, podemos ter uma relação de alteridade e de reciprocidade entre as partes.

Em outro contexto, Bourdieu, Chamboderon e Passeron (2002) atentam para os diferentes significados que uma mesma pergunta ou resposta podem ter, dependendo da condição e posição social dos(as) entrevistados(as). Sujeitos separados pelas diferenças de cultura, associadas à origem de classe, constroem sentidos diversos para as temáticas e problemáticas apresentadas. 

de trabalho econômico maior, a um tempo de trabalho para a reprodução social mais elevado ou a um tempo fragmentado que compromete as diversas dimensões de suas vidas.

Para compreendermos essas configurações do trabalho docente, trazemos alguns trechos de análise das jornadas e dos ritmos no cotidiano de professoras e professores, levando em consideração algumas dimensões do uso do tempo, sem perder o olhar para as relações de gênero nele e por ele configuradas e difundidas. fornecendo entrevistas e preenchendo os diários de uso do tempo, foi possível apreender com maior riqueza de detalhes suas condições de vida, incluindo os ritmos e jornadas de trabalho [2].

Fátima tem 28 anos e nasceu em São Paulo. Começou a trabalhar desde cedo, aos 15 anos. Conta que, naquela época, era muito fácil conseguir emprego. Em seu meio social, todo mundo trabalhava : suas amigas, seus primos e seus irmãos. Seu pai falava que era bom trabalhar, apesar de ele não forçar. Depois que terminou o ensino médio, ficou em dúvida se continuava os estudos, mas incentivada pelo pai e pelo marido, namorado na época, fez cursinho pré-vestibular e, depois de muito estudo, conseguiu entrar na USP. 
Formou-se em Letras, em 2004, aos 26 anos. Poderia ter se formado antes, mas trancou a faculdade por um ano e meio para ir se encontrar com o namorado nos Estados Unidos. De volta ao Brasil, casaram-se e, hoje, moram perto da casa de seus pais. 0 marido tem 32 anos, é taxista e tem o ensino médio completo. Por opção, ainda não têm filhos.

Hoje, sua rotina nos dias de semana resume-se em trabalhar de manhã na escola municipal e, à noite, na escola estadual. Durante as tardes, almoça, descansa um pouco, prepara aulas da semana, lê livros e jornal. Nas quintas e sextas, faz serviços de limpeza da casa. Nos finais de semana, fica sozinha durante as tardes de sábado, pois o marido trabalha. Aproveita o dia para preparar as atividades escolares da semana, lavar roupa ou resolver coisas na rua. Aos domingos, costuma passar roupa e ficar com o marido. Nas manhãs de sábado e domingo, saem para caminhar. Gostam de sair, ir ao cinema e, às vezes, ao teatro.

76 Fernanda tem 36 anos, nasceu em Sorocaba, interior do estado de São Paulo. Na educação básica, estudou somente em escolas públicas na cidade de Sorocaba. No SESI, estudou até a $4^{a}$ série. $O$ restante do ensino fundamental fez em uma escola estadual em um bairro de periferia. Cursou o magistério em uma escola municipal e a graduação em História nas Faculdades Integradas Dom Aguirre, hoje UNISO - Universidade de Sorocaba. Em 2002, passou no concurso da Prefeitura Municipal de São Paulo e do Estado de São Paulo. Como já trabalhava na escola estadual em Vargem Grande Paulista e, quando foi convocada, não havia vagas em Sorocaba, efetivou-se nesta escola, na qual se encontra até hoje, não só como professora, mas também, desde 2003, como zeladora. É solteira e tem um filho de 17 anos, que, hoje, mora com o pai em Sorocaba e trabalha com um tio paterno. Quando assumiu a zeladoria da escola, morava com a avó e com o filho. Após a volta do filho para Sorocaba e a morte da avó, levou sua mãe para morar com ela na escola. Neste meio tempo, teve um relacionamento de quatro anos com um catarinense. Ela e o marido moravam na escola, mas por diversos motivos separaramse.

Durante as manhãs, trabalha na escola municipal. Sai de casa às $4 \mathrm{~h} 30$ para iniciar as aulas às $7 \mathrm{~h}$. Após as aulas, por volta de $13 \mathrm{~h} 30$, são mais duas horas de deslocamento para entrar direto nas aulas do Estado. No final da tarde, nas segundas, quartas e sextas, após o jantar e um banho rápido, entra novamente em sala de aula. Somente nas terças e quintas não tem aula à noite, mas, nestes momentos, costuma preparar aulas, corrigir provas e atividades ou navega na Internet, checa os e-mails, faz telefonemas.

Os sábados e domingos são reservados para o filho, que "vai pra casa todos os finais de semana". Geralmente, utiliza também os finais de tarde de domingo para preparar as aulas e corrigir atividades. Ultimamente, tem poucas tarefas domésticas, pois sua mãe faz todo o serviço de casa. Responsabiliza-se pelas compras e por algumas atividades nos finais de semana, quando sua mãe vai para Sorocaba visitar a irmã mais nova. Ela e o filho saem, de vez em quando, mas "lazer é muito caro, né ?". Gostam muito de ficar em casa, lendo, assistindo a filmes. Gosta de cozinhar para o filho e fazer tudo o que lhe agrada. Fernanda tem uma vida corrida, com dois cargos que comprometem a maior parte de seu dia. No entanto, não pode abrir mão de nenhum dos cargos, uma vez que é arrimo de família.

79 Marcelo tem 33 anos e nasceu em São Paulo. É solteiro e mora com a família. O pai e a mãe aposentaram-se, mas resolveram continuar trabalhando para manter o padrão de vida. Hoje, além dessas duas fontes de renda, ainda têm casas alugadas: Eles têm 
condições e não precisam da minha renda. E é essa uma das razões que possibilitam que Marcelo more com os pais, trabalhe menos e possa dedicar-se aos estudos.

Formou-se em Tecnologia da Construção Civil pela FATEC. Ainda no primeiro ano de faculdade, aos 19 anos, começou a lecionar Matemática e Desenho Geométrico no Estado como professor contratado e, ao mesmo tempo, estagiava no Grupo de Computação Gráfica da FATEC.

81 Depois de formado, sempre dando aulas no Estado, trabalhou como projetista de uma empresa de ar condicionado e como técnico na Eletropaulo. Durante um ano e meio, substituiu um professor no SENAI. Resolveu abraçar a carreira de professor e fez a licenciatura em Matemática, em um curso de complementação pedagógica, na Universidade Mackenzie. Em 1999, passou no concurso do Estado de São Paulo, mas não pôde assumir por problemas burocráticos e, desanimado, resolveu não pegar mais aulas. Em 2002, passou no concurso da Prefeitura Municipal de São Paulo e, por quatro anos, também lecionou em uma escola particular.

82 Hoje, trabalha pela manhã na escola municipal e, às tardes, duas ou três vezes na semana, presta serviços educacionais para um Portal na Internet. Escreve artigos, planos de aula e responde dúvidas de professores(as). É um trabalho mais suave, em termos de carga horária. No final da tarde, faz ginástica em um clube do qual é sócio. Quando está fazendo algum curso, como os dois de especialização já realizados, utiliza as noites para frequentar disciplinas e para fazer as leituras. Neste momento, está com as noites livres até que comece as aulas do Mestrado em Educação na USP, no segundo semestre.

83 Pedro tem 32 anos e nasceu em São Paulo. É casado, tem um filho de três anos e, atualmente, mora na casa da sogra devido à construção de sua casa. É professor concursado de Ciências, na Prefeitura de São Paulo e de Química, no Estado de São Paulo. Na escola municipal, assumiu, neste ano, as aulas de informática para estudantes de $1^{\mathrm{a}}$ a $8^{\mathrm{a}}$ série. Como leciona para as duas fases do ensino fundamental, tem aulas pela manhã e à tarde. Ele avalia que o trabalho com as crianças menores tem lhe causado certa dificuldade, principalmente com aquelas que estão na fase de alfabetização, mas garante que tem gostado bastante da experiência. No Estado, leciona Química para estudantes do ensino médio, à noite.

Mesmo que não tenha períodos fechados de aula, seu dia é quase todo comprometido com as aulas. Nos momentos em que não está na escola, precisa resolver as questões referentes à construção de sua casa e à reforma de uma casa do pai, uma vez que ele é o responsável pelas obras. Cuida de seu filho na hora do almoço e nas aulas de natação. No tempo restante, o menino fica com a avó paterna ou com a moça responsável pelo cuidado da casa. À noite, fica com a mãe, após sua chegada do trabalho. O sogro e a sogra trabalham em uma cantina de escola o dia todo.

Atualmente, os finais de semana estão quase todos comprometidos com as obras. Além disso, neste ano, ressalta que está com uma rotina atípica. Em 2006, trabalhava durante as manhãs $\mathrm{e}$ as noites. As tardes eram reservadas para o cuidado com o filho (alimentação, higiene, sono, passeios, leituras, atividades), a limpeza da casa e as atividades escolares (planejamento de aulas, correção de atividades). Neste ano, tem poucos momentos de lazer. Gostaria de voltar a ir ao parque com o filho, ao cinema e na casa de parentes. Apesar das mudanças, quando está no trabalho, as preocupações com o filho não desapareceram. Pelo fato de a esposa trabalhar em uma empresa privada, 
sendo mal vistas as faltas de funcionários(as), Pedro tenta garantir que ela não tenha nenhum tipo de preocupação, nem mesmo quando o filho está doente.

Diante desse perfil geral do grupo de docentes pesquisados(as), e, mais especificamente, das professoras e dos professores entrevistadas(os), já é possível perceber que tanto professores quanto professoras, em sua maioria, possuem jornadas e ritmos intensos de trabalho, seja devido ao tempo de trabalho econômico maior, ao tempo de trabalho para a reprodução social mais elevado ou ao tempo fragmentado que compromete as diversas dimensões de suas vidas.

O tempo, para professoras e professores, é quase sempre o inimigo da liberdade. Frases como não tenho tempo, preciso de mais tempo e não há tempo suficiente são recorrentes no cotidiano escolar. Além disso, o tempo contém uma dimensão fundamental na configuração do trabalho docente : por meio dele constituem-se restrições objetivas e opressoras, mas também horizontes de possibilidades e limitações subjetivamente definidos. $O$ tempo estrutura o trabalho e é estruturado por ele (Hargreaves, 1994).

Correria, cansaço, decepção, falta de tempo, ansiedade, desgaste e estresse são os sentimentos aos quais muitos professores e professoras se referiram para expressar o uso do tempo em suas vidas. Outros sentimentos negativos, como preocupação, massacre e tristeza, também foram citados. Por outro lado, embora com menor freqüência, sentimentos positivos, como aprendizagem, sabedoria, experiência, mudança, vitalidade, evolução e gratificação foram salientados tanto pelo grupo de docentes que responderam ao questionário quanto pelos quatro docentes que participaram das entrevistas e preencheram os diários de uso do tempo.

89 Andy Hargreaves (1994), em sua discussão sobre as dimensões do tempo, defende que, além de seu caráter fixo e objetivo, o tempo é também, essencial e inevitavelmente, um fenômeno subjetivo. 0 que se tem e o que se chega a considerar como tempo objetivo, incluído na forma do tempo do relógio é, na realidade, uma convenção social, intersubjetiva, um produto da ação humana. Os horários e os calendários, que podem nos parecer externos, limitadores e inalteráveis, são, na realidade, o produto de definição e de decisão subjetivas.

Dessa maneira, é possível questionar a aparente neutralidade da distribuição temporal vigente e investigar suas origens e interpretações sociais. Esse aspecto pertence à dimensão fenomenológica do tempo. Nela, o sentido interno do tempo pode variar de pessoa para pessoa, pois o tempo depende das ocupações e do trabalho dos sujeitos, aliados às suas preocupações, aos seus interesses e aos seus projetos. O tempo é subjetivo, vivido, cada pessoa tem uma experiência do tempo única.

91 Conceitualmente, nos termos de Joffre Dumazedier (1973), o lazer está isento de toda e qualquer obrigação. Para a maioria dos(as) docentes pesquisados(as), assistir televisão, ir ao cinema, ao teatro, navegar na internet, dormir e ler - até mesmo leituras profissionais - são as atividades realizadas em seu tempo livre. Procuro fazer atividades de lazer com a familia ou dormir, Gosto muito de ficar em casa sem fazer nada, dormindo. Acho que até por conta do desgaste mental do dia-a-dia, dizem. Há também outras atividades de lazer, menos citadas : ir ao shopping, a restaurante, a exposições de arte, a feiras; sair para dançar ; viajar ; praticar esportes; ir à academia, à igreja, ao salão de beleza ; fazer trabalhos artesanais; caminhar ; e ir ao clube. 
Contrariamente à noção de lazer proposta por Dumazedier (1973), para os(as) professores(as) casados(as), mesmo as atividades que dão prazer e os(as) entretêm estão ligadas à família e aos(às) filhos(as). São lazer e obrigação, ao mesmo tempo.

Quando se formou em Ciências, com habilitação em Química, Pedro trabalhava em uma indústria química e, nas horas vagas, começou a lecionar. Em seguida, resolveu abandonar a indústria e dedicar-se somente ao magistério :

$\mathrm{Na}$ verdade, eu me identifiquei com essa coisa de dar aula. Apesar das dificuldades tirarem um pouco do brilho, as condições, o ambiente, tiram um pouco desse entusiasmo, mas é uma coisa legal você trabalhar com pessoas, mesmo não tendo aquela coisa da conclusão do trabalho. Você não vê aquela conclusão. Não é que nem o engenheiro - começa uma casa e termina. Ele vê a coisa acabada, mas a gente não. Tem uma certa frustração nisso, mas eu acho que é gratificante você trabalhar com... foi muito proveitoso pra mim, até pra evolução pessoal, experiência de vida, né?

Em 2007, mesmo com uma rotina muito intensa, por causa das obras e das aulas nos três períodos, Pedro ainda está motivado com o trabalho: Eu acho gratificante trabalhar com as crianças. E, nesse ano, eu estou gostando de trabalhar mais com os pequenos, não tanto com os grandes. [...] os pequenos estão me fascinando mais.

Fernanda também tem sentimentos positivos com relação ao trabalho, apesar das dificuldades com estudantes, de sua rotina intensa e dos deslocamentos diários.

Eu sempre tive o sonho de ser professora. Eu queria ser professora e bailarina. Eu fiz muitos anos de balé, mas balé no Brasil não é valorizado, né ? Então, eu optei realmente por ser professora. Então, é um sonho antigo. Eu faço o que eu quero, o que eu gosto, o que eu planejei e objetivei na minha vida.

No entanto, pondera aspectos negativos em relação à falta de compromisso de estudantes e a conivência de pais e mães e governo em relação ao cumprimento das normas da escola.

Baseando-se em pesquisa realizada por Werner, Hargreaves (1994) assinala que o tempo vivido por docentes choca-se com os supostos temporais administrativos. As excessivas exigências temporais pressionam e causam ansiedade, além do sentimento de culpa por não conseguirem cumprir o cronograma imposto. Nesse momento, surgem solicitações de docentes para dispor de mais tempo para planejamento e para a aplicação das inovações pedagógicas.

98 Além da excessiva carga de trabalho, a realização dos serviços escolares em casa - seja para planejamento de aulas, atividades, leituras e estudos, seja para correção de provas, exercícios e trabalhos - aumenta a jornada e impede que o professor se dedique exclusivamente a uma escola, ocasionando redução na qualidade dos serviços prestados, salienta Marcelo.

99 Ao analisar os relatos sobre os últimos cinco anos da vida dos(as) 19 docentes pesquisados(as), é possível perceber algumas mudanças no tempo dedicado ao magistério : enquanto algumas pessoas diminuíram a carga horária de trabalho, outras a aumentaram, seja por motivos financeiros, seja por envolvimento profissional. Por ter aumentado o tempo dentro das escolas, uma professora afirma que diminuiu o tempo dedicado aos estudos, à vida pessoal e familiar. Diminuiu a qualidade de vida. 
100 Algumas professoras diminuíram o tempo para preparação das aulas, por falta de tempo ou por considerarem que a experiência e a segurança adquiridas permitem menor dedicação. De outro lado, estão docentes que aumentaram o tempo com os estudos, como Pedro, que tem se dedicado a pesquisar assuntos de meu interesse que pertencem a outras disciplinas, como história, geografia, etc.

101 Se pudessem mudar os usos de distribuição do tempo em suas vidas, a maioria trabalharia menos, uma vez que consideram que o trabalho docente exige muito esforço depois das aulas - estudo, preparação de atividades, etc..

102 Redução de um período de trabalho, menos tempo em sala de aula e ausência de tarefas burocráticas são os desejos mais frequentes. Caso esta fosse a situação do(a) trabalhador(a) docente, segundo eles e elas, teriam tempo para estudos, pesquisas, lazer, incluindo viagens, esportes ou academia, mais tempo para a família ou, simplesmente, para descansar. No entanto, devido aos baixos salários, é preciso acumular dois ou três empregos para conseguir pagar as contas ou ter um mínimo de conforto.

103 Por outro lado, apesar da desvalorização do salário e das extensas jornadas de trabalho, foram também ressaltadas algumas vantagens vistas pelo grupo: há maiores oportunidades e ofertas de emprego. Além disso, as férias duas vezes por ano são outro ponto positivo apontado. Em comparação entre a escola pública e a privada, a maioria acredita que há, na última, mais cobrança, mais pressão e mais controle. Com isso, os(as) docentes dedicam-se também por medo do desemprego. Ao contrário, na escola pública, devido à estabilidade de emprego, professores e professoras dedicam-se menos, principalmente no preparo de aulas.

104 Marcelo é o único docente que considera que sua rotina está boa e avalia que o que eu faço é o que todo mundo deveria fazer. [...] Um tempo pra preparar aula, pra pesquisar, pra estudar, enfim. Mas eu sou exceção, né? Não sou a regra. Se pudesse mudar alguma coisa, seria o horário de início das aulas. Gostaria de acordar um pouco mais tarde, pois acha que o período escolar começa muito cedo. Começa às 7 h. E 7h tá todo mundo sonolento, ninguém tá muito preparado ainda. Escola deveria começar às $8 h$, talvez.

105 Poderíamos justificar essa condição pelo fato de Marcelo ser solteiro e ainda morar com os pais? Ser casado(a) e ter filhos(as) faz com que as pessoas - no caso, os(as) docentes - tenham maiores tempos de trabalho? Trabalho para a reprodução econômica para aumentar a renda e garantir o mínimo de conforto para a família? Trabalho para a reprodução social, uma vez que é preciso maior dedicação aos afazeres domésticos e ao cuidado com os(as) filhos(as)?

106 Apesar de considerar sua rotina ideal para qualquer docente, Marcelo está meio desanimado. Não desanimado pra preparar aula. Assim não. Eu sou animado pra fazer isso. Tentar fazer uma aula diferente. Eu estou desanimado com os resultados que eu estou obtendo. Considera que o comportamento do grupo de estudantes está pior a cada dia e, com o passar do tempo, a paciência para lidar com a indisciplina vai diminuindo. A relação professor(a) aluno(a) é fator de desgaste e desmotivação.

107 Como sempre gostou de estudar e tem procurado crescer profissionalmente, Marcelo tem planos de seguir na carreira da docência no ensino superior ou na área de cultura. Tinha vontade de trabalhar com arquitetura e paisagismo, mas é muito complicado você começar do zero, sendo que você investiu 15 anos numa área. Com relação aos planos 
pessoais, é continuar fazendo esporte, talvez morar numa cidade mais calma, não sei ainda. Eu não fiz muitos planos ainda.

Fátima tem sensação parecida com a de Marcelo com relação à sua possibilidade de descanso, mas gostaria de ter somente um cargo. Avalia que sua situação atual de vida é melhor que a de muitos docentes e justifica : até tenho mais tempo, porque eu ainda chego em casa e dá pra eu descansar, né ? Dá pra eu ainda fazer alguma coisa, mas não é o suficiente ainda. Com relação ao ano de 2006, sua rotina melhorou bastante: Eu trabalhava de manhã, chegava em casa correndo, almoçava e já ia pra outra escola. Eu chegava $18 \mathrm{~h} 30 \mathrm{em}$ casa e não conseguia fazer mais nada. Nada. Eu estava quebrada. Eu sentava no sofá e lá eu ficava. Se pudesse escolher entre os dois cargos, Fátima ficaria na escola municipal, porque considera mais organizado, tem menos alunos nas salas, a carreira também é melhor, a evolução profissional. Além disso, se conseguir ingressar no Mestrado em Letras vai abandonar um cargo [risos]. Com certeza, porque com dois cargos e um mestrado não dá.

Apesar de todas as dificuldades, Fátima ainda tem o ideal de trabalhar em escola pública:

Porque eu vim de uma escola pública, né ? Eu ainda tenho esse papel que eu quero cumprir. Se precisasse escolher outra profissão, acho que eu seria bibliotecária [risos]. Talvez. Às vezes, eu até penso em fazer algum curso assim. Penso assim bem distante, entendeu ? Mas eu não sei se vou fazer um dia.

111 Assim como Fátima, Fernanda gostaria de voltar a estudar, fazer uma especialização ou mestrado e, por isso, um cargo somente seria o ideal. Mesmo considerando melhor o público da escola estadual em que trabalha, Fernanda escolheria a escola municipal, se pudesse optar por um emprego apenas, principalmente, por causa da evolução funcional.

112 Se pudesse optar por outra profissão, diz que talvez escolhesse serviço social. Fernanda gosta de política, de atendimento ao público, de recepção, de comunicação : Eu acho que eu sou bastante polivalente nesse sentido. Mas o que eu gosto mesmo é de lecionar. Eu adoro dar aula.

113 Quando questionados se consideram que há diferenças no uso dos tempos de professores e professoras, a maioria respondeu que as professoras têm maiores jornadas, devido à sobreposição do trabalho econômico e doméstico :

As professoras, além das duas escolas, ainda têm a casa, os filhos e os parentes para se ocuparem.

Temos tripla jornada de trabalho, pois muitas de nós somos separadas e temos a responsabilidade plena sobre os filhos.

114 Fernanda cita o seu exemplo para defender que as mulheres possuem uma carga maior de trabalho que os homens :

Depois de um dia de trabalho, eu tinha que lavar louça, fazer a janta, e eu estava sem comer, porque não dava tempo, fazer janta. Então, começavam as brigas, porque eu não consigo ser submissa e eu falava. Não vou morrer de câncer. Tudo o que eu tenho pra falar, eu falo. Eu sou bem sincera. E eu falava pra ele. Tentava argumentar, mas era inútil. Daí, dava briga, ele saía, chegava de madrugada. E eu permiti tanto tempo essa situação, eu nem sei como, por causa do meu perfil feminista. Talvez porque eu achava que ele era dependente de mim. Não existia amor mais. Existia uma responsabilidade com aquilo que você cativou. "O que vai acontecer? Ele tá longe da família, 
tá sem emprego, praticamente. De vez em quando que aparece. O que vai ser desse homem ?". Só que, assim, paciência tem limite. Até que rompeu, foi uma ruptura mesmo, de uma forma mais abrupta possível, mas valeu a pena, porque ele aprendeu a crescer. Começou a crescer e a mudar o perfil, porque senão não ia ter sobrevivência.

115 Ao falar sobre a vida de outras professoras, Fernanda chega à conclusão de que quando há separação entre o casal, geralmente, o homem fica em uma situação mais cômoda :

Eu tenho vários exemplos, inclusive de uma colega, uma companheira de trabalho aqui. Ela se separou aos 29 anos de idade. O marido a abandonou, sozinha, com três filhas. Ela não trabalhava. Ela terminou o magistério, ela fez faculdade, ela tem dois cargos na Prefeitura. Nunca mais ela se casou, nem namorou, nada. Ela se completou sozinha. E, hoje, ela tem a casa dela, as filhas dela, as três têm faculdade. A última está terminando a faculdade, a caçula. São bem orientadas, têm os seus empregos.

116 Para Fernanda, os professores do CEU também trabalham muito, às vezes, em até três escolas, mas, com relação às tarefas domésticas, eles não precisam. Não, porque daí tem a mulher, né ? Há quem faça.

Fernanda entrou em contato com as discussões sobre as desigualdades de gênero quando ainda fazia parte do PT - Partido dos Trabalhadores. Depois, na Associação dos Professores do Ensino Oficial do Estado de São Paulo (APEOESP), aprofundou a discussão e me engajei na política de gêneros, dentro da APEOESP, que são setoriais e a gente sempre levava para o congresso essa questão da mulher, essa questão do aborto, essa questão da mulher negra.

118 No entanto, traz uma concepção essencialista e generalizada do ser mulher ou ser homem ao defender que as mulheres são mais práticas e os homens são mais teóricos. Para ela, esse é o motivo das professoras se dedicarem mais à educação, talvez porque elas tratem mais a questão da maternidade, que elas se identifiquem mais com os alunos. É como se ele fosse meu filho.

119 Apesar de fazerem parte da realidade de muitas mulheres, as situações descritas pela professora não podem ser generalizadas nem tomadas como condição natural feminina. Por outro lado, nem sempre os homens vivem a paternidade da maneira por ela descrita, nem têm uma relação tão distante de seus alunos, como a professora menciona.

120 Marcelo concorda que a responsabilidade com as atividades domésticas e com os(as) filhos(as) recai mais sobre as mulheres, mas, ao analisar as jornadas de trabalho total, no caso de professores ou professoras casadas, fica evidente que as jornadas se igualam :
As mulheres pegam jornada dupla e se preocupam com a casa, as casadas, no geral, das professoras que eu conheço. $\mathrm{E}$ os professores casados pegam jornada tripla. [...] Nós temos um professor lá que tem 70 aulas. Ele tem escola municipal, estadual, dá o acúmulo dele de cargo e ainda tem uma particular. Tudo isso na ansiedade de educar bem os filhos, enfim.

121 Já na percepção de Marcelo, no caso de docentes solteiros(as), a situação se iguala, independentemente de ser homem ou mulher: Quando pegam mais aula é mais pra ter mais dinheiro, pra trocar um carro, comprar uma casa. Não é aquela necessidade assim "Ai, a minha família vai passar fome". É outro tipo de necessidade. 


\section{Considerações finais}

Apesar do pequeno número de professores e professoras pesquisados(as), foi possível perceber que tanto as mulheres quanto os homens possuem extensas jornadas totais de trabalho, que incluem tempo de trabalho econômico e tempo de trabalho para a reprodução social. E, ao contrário de outras profissões, as professoras não possuem empregos temporários, nem de tempo parcial (Hirata, 2002), que "facilitariam" a conciliação com as atividades de casa e o cuidado com os filhos e/ou com o marido. 0 trabalho doméstico é, na maioria das vezes, executado entre turnos, no horário de almoço ou nos finais de semana.

Os professores também possuem ritmos intensos e jornadas extensas, nas quais se incluem também os serviços domésticos. $\mathrm{E}$ as professoras, por outro lado, também possuem grandes responsabilidades pelo sustento da casa. Por isso, as vivências e os significados do trabalho docente são diversos daqueles previstos pelas teorias da divisão sexual do trabalho, por serem múltiplas as preocupações, os interesses e os projetos.

4 O caso mais significativo é o de Pedro que, mesmo com uma extensa jornada de trabalho econômico, ainda tem preocupações com o filho pequeno. Mesmo tendo seu tempo praticamente ocupado com as atividades escolares e com as obras, dedica-se ao cuidado do filho e, ainda, preocupa-se em resolver todas as questões que se referem a ele, fazendo com que a esposa não tenha que faltar ao trabalho para atender alguma eventualidade.

De outro lado, as mulheres nem sempre são as responsáveis pelo serviço doméstico, como é o próprio caso de Fernanda, que conta com sua mãe para isso.

Finalmente, cabe indagar : se tanto as mulheres quanto os homens possuem extensas jornadas de trabalho total, podemos dizer que os sentimentos negativos que envolvem a profissão atingem ambos os sexos?

7 Poderíamos concordar com um dos estudos apresentado por Silva e Carlotto (2003), o qual defende que são os homens os mais atingidos, uma vez que o peso da responsabilidade familiar e as expectativas de sucesso, de competição e de desenvolvimento geram uma insatisfação maior no trabalho? E o que dizer das considerações das próprias autoras, que defendem que as mulheres são as mais prejudicadas, uma vez que elas são "mais emotivas, mais envolvidas com o cuidado, alimentação e preocupação com o bem-estar do próximo" ? Pedro, casado e também com um filho, percebemos que os significados positivos ou negativos com relação à profissão atribuídos às mulheres ou aos homens não podem ser fixos, imutáveis e colados ao sexo de quem exerce a docência. Fernanda carrega a responsabilidade de ser a provedora da casa, considerada masculina. Ambos têm sentimentos positivos e negativos em relação ao trabalho, mesmo que os motivos não sejam os mesmos. Apesar de seu filho morar com o pai, é Fernanda quem se ocupa mais de seus cuidados, atividade típica do sexo feminino. Pedro, por sua vez, divide o sustento da casa com sua esposa e dedica muitas horas de seu dia ao serviço doméstico e ao cuidado com seu filho pequeno. 
Parece, portanto, que apenas ser homem ou ser mulher não determina o uso dos tempos cotidianos, nem os significados a eles atribuídos. Outras variáveis precisam ser levadas em conta, tais como, socialização de gênero, idade, estado civil, apoio familiar, apoio institucional, entre outras.

Nesse sentido, a análise dos questionários, das entrevistas e dos diários de uso dos tempos mostrou que algumas características apontadas por Dedecca (2004) para a configuração da divisão sexual do trabalho em geral não poderiam se estender aos(às) docentes pesquisados(as).

131 Foi preciso, portanto, desconstruir algumas dicotomias apresentadas pela teoria e se dar conta de que tanto os professores quanto as professoras possuíam extensas jornadas de trabalho total. No entanto, esse grupo se divide em dois. O primeiro possui grandes jornadas de trabalho econômico e pouca ou quase nenhuma atividade relacionada à reprodução social, sendo que descanso e lazer não estão incluídos. $O$ fato de trabalhar em duas ou três escolas ou em outra atividade fora do magistério já faz com que seus tempos de trabalho remunerado sejam grandes o suficiente para ocuparem a maior parte de seus dias, até mesmo nos finais de semana, como é o caso de Fernanda.

O segundo grupo envolve a maioria dos(as) docentes, que são aqueles(as) que também possuem grandes jornadas de trabalho econômico, além das tarefas que envolvem o cuidado com a casa e/ou com filhos(as). 0 acúmulo dos dois tipos de jornada faz com que suas rotinas sejam extremamente sobrecarregadas. Neste segundo grupo, está Fátima e Pedro. Marcelo não se enquadra em nenhum dos dois grupos, pois não possui jornada extensa de trabalho, nem econômica nem para a reprodução social.

De certa maneira, esta divisão vai ao encontro da afirmação do próprio Marcelo. Segundo ele, as mulheres casadas têm dupla jornada de trabalho econômico e ainda têm preocupações com a casa. Os homens casados, por sua vez, por terem a responsabilidade de serem os provedores, têm tripla jornada de trabalho e, em contrapartida, não possuem atividades ligadas à reprodução social. O que diferencia nossas considerações das de Marcelo é que fazemos um recorte de gênero e não de sexo. Essas diferenciações dos tempos de trabalho realmente acontecem no cotidiano docente, mas não podem ser separadas entre homens e mulheres ou, mais especificamente, entre professores e professoras.

Portanto, a análise aqui apresentada procurou apreender como são vividas e sentidas as jornadas de trabalho no cotidiano de professoras e professores do Ensino Fundamental II de uma escola do município de São Paulo. Por meio dos questionários, das entrevistas e dos diários de uso dos tempos, foi possível perceber que as "práticas miúdas do cotidiano docente", permeadas pelas relações de gênero e classe, entrecruzam-se e produzem situações que ora reproduzem ora transgridem aquelas que se referem às mulheres e aos homens, em geral.

135 É importante que a temática sobre o cotidiano docente passe a ser discutida com mais seriedade, considerando que, muitas vezes, as extensas jornadas de trabalho total são decorrentes dos baixos salários. Além de políticas públicas que valorizem a profissão e regulamentem as jornadas de trabalho econômico, devem-se levar em conta, como Dedecca (2004) salienta, as demais dimensões do tempo para que professoras e professores não fiquem sobrecarregados(as) com as atividades escolares realizadas em casa e as tarefas de cuidado com a casa, familiares e, principalmente, filhas e filhos pequenos. 


\section{BIBLIOGRAFIA}

Abramo, L., \& Abreu, A. (orgs.) (1998). Gênero e trabalho na sociologia latino-americana. São Paulo/Rio de Janeiro : ALAST/SERTl.

Alvarenga, C. F. (2008). Relações de gênero e trabalho docente : jornadas e ritmos no cotidiano de professoras e professores. Dissertação de Mestrado apresentada na Faculdade de Educação da Universidade de São Paulo. São Paulo.

Antunes, R. (2006). Os sentidos do trabalho : ensaio sobre a afirmação e a negação do trabalho. (8 edição). São Paulo : Boitempo.

Bourdieu, Chamboderon, J. C., \& Passeron, J. C. (2002). A profissão de sociólogo : preliminares epistemológicas. Trad. Guilherme João de Freitas Teixeira. Petrópolis, RJ : Vozes.

Bourdieu, P. (1997). Compreender. In Pierre Bourdieu (Coord.), A miséria do mundo (pp. 693-713). Petrópolis, Rio de Janeiro : Vozes.

Brasil, IBGE, Instituto Brasileiro de Geografia e Estatística (2011). Desocupação fica em 5,3 \% em dezembro e fecha 2010 numa média de 6,7 \%. Disponível em : http://www.ibge.gov.br/home/ presidencia/noticias/noticia_visualiza.php?id_noticia=1808\&id_pagina=1. Acessado em 12 de janeiro de 2012.

Bruschini, M. C. A. (2000). Gênero e trabalho no Brasil : novas conquistas ou persistência da discriminação ? (Brasil, 1985/95). In Maria Isabel Baltar da Rocha (Org.), Trabalho e gênero : mudanças, permanências e desafios. (pp. 13-58) ABEP, NEPO/UNICAMP e CEDEPLAR/UFMG. São Paulo : Editora 34.

Bruschini, M. C. A., \& Lombardi (1999). Médicas, arquitetas, advogadas e engenheiras : mulheres em carreiras profissionais de prestígio. Revista Estudos Feministas, 7, 1 e 2, 9-24.

Butler, J. (1993). Bodies that matter. New York/Londres : Routledge.

Carvalho, M. J. S. (2001) Educação, gênero e temporalidades : uma análise dos usos do tempo de crianças de classe popular da periferia de Porto Alegre. Relatório de pesquisa. Porto Alegre : Universidade Federal do Rio Grande do Sul. 
Carvalho, M. P. (1999). No coração da sala de aula : gênero e trabalho docente nas séries iniciais. São Paulo : Xamã.

Costa, M. (1995). Trabalho docente e profissionalismo. Porto Alegre : Sulina.

Dedecca, C. (2004). Tempo, trabalho e gênero. São Paulo : mimeo.

Dumazedier, J. (1973). Lazer e cultura popular. São Paulo : Perspectiva.

Elias, N. (1998). Sobre o tempo. Tradução de Vera Ribeiro. Rio de Janeiro : Jorge Zahar.

Fausto-Sterling, A. (2000). Sexing the Body : gender politics and the construction of sexuality. New York : Basic Books.

Foucault, M. (1997). A arqueologia do saber. (5ª edição). Tradução de Luiz Felipe Baeta Neves. Rio de Janeiro : Forense.

Giddens, A. (1989). A constituição da sociedade. São Paulo : Unesp.

Hargreaves, A. (1994). Changing teachers, changing times : teachers work and culture in the postmodern age. New York : Teachers College Press.

Hirata, H. (1998). Reestruturação produtiva, trabalho e relações de gênero. Revista Latinoamericana de Estudios del Trabajo : Gênero, Tecnologia e Trabalho, 4, (7) 5-28.

Hirata, H. (2002). Nova divisão sexual do trabalho ? Um olhar voltado para a empresa e a sociedade. São Paulo : Boitempo.

Hypolito, Á. M. (1997). Trabalho docente, classe social e relações de gênero. Campinas : Papirus. Coleção Magistério : formação e trabalho pedagógico.

Kergoat, D. (2000). Division sexuelle du travail et rapports sociaux de sexe. In : Helena Hirata, Françoise Laborie, Hélène Le Doaré e Danièle Senotier (Coords.), Dictionnaire Critique du Féminisme (pp. 35-44). Paris : PUF.

Le Ven, M. M., Faria, É., \& Motta, M. H. S. (1997). História Oral de vida : o instante da entrevista. In Olga Rodrigues de Moraes von. Simson (Org), Os desafios contemporâneos da História Oral. Campinas : Unicamp, Centro de Memória.

Louro, G. L. (1989). Magistério de 1o grau : um trabalho de mulher. Educação \& Realidade, 14, 2, jul./dez., 31-39.

Melucci, A. (2004). O jogo do eu : a mudança de si em uma sociedade global. (versão original, em italiano, de 1991). São Leopoldo : Unisinos.

Michelat, G. (1987). Sobre a utilização da entrevista não-diretiva em Sociologia. In Michel Thiollent, Crítica metodológica, investigação social e enquete operária (pp. 191-211) (5ª edição). São Paulo : Polis.

Nogueira, C. M. (2004). A feminização do mundo do trabalho : entre a emancipação e a precarização. Campinas : Autores Associados.

Posthuma, A. C. (1998). Mercado de trabalho e exclusão social da força de trabalho feminina. IN L. Abramo e Alice Rangel de Paiva Abreu (Orgs.), Gênero e Trabalho na sociologia latino-americana (pp. 21-82). São Paulo/Rio de Janeiro : ALAST.

Queiroz, M. I. P. (1985). Variações sobre a técnica de gravador no registro da informação viva. (2 $2^{a}$ edição). São Paulo : CERU e FFLCH/USP.

Scott, J. W. (1994). A mulher trabalhadora. In Georges Duby e Michelle Perrot, História das mulheres no ocidente (pp. 443-475). Porto : Afrontamentos. 
Scott, J. W. (1995). Gênero : uma categoria útil para a análise histórica. Educação \& Realidade, 20 (2) jul./dez., 71-99.

Scott, J. W. (1998). Entrevista com Joan Wallach Scott - entrevista a Miriam Grossi, Maria Luiza Heilborn e Carmem Rial. Estudos Feministas, 6, 1, 114-124.

Silva, G. N., \& Carlotto, M. S. (2003). Síndrome de burnout : um estudo com professores da rede pública. Psicologia Escolar e Educacional, 7, 2, 145-153.

Souza-Lobo, E. (1991). A classe operária tem dois sexos : trabalho, dominação e resistência. São Paulo : Brasiliense.

Teixeira, I. A. C. (1998). Tempos enredados : teias da condição professor. Tese de Doutorado. Belo Horizonte : Faculdade de Educação da Universidade Federal de Minas Gerais.

Thiollent, M. (1987). Crítica metodológica, investigação social e enquete operária. (5a edição). São Paulo : Polis.

Venturi, G., Recamán, M., \& Oliveira, S. (Orgs.) (2004). A mulher brasileira nos espaços público e privado. São Paulo : Fundação Perseu Abramo.

Vianna, C. (2002). Contribuições do conceito de gênero para a análise da feminização do magistério no Brasil. In Maria Christina Siqueira de Souza Campos e Vera Lúcia Gaspar da Silva (Orgs), Feminização do magistério : vestígios do passado que marcam o presente (pp. 39-67). Bragança Paulista : EDUSF.

Vidal, D. G. (2006). Um olhar sobre os estudos de gênero em história da educação no Brasil. In Christiani Cardoso Morais, Écio Antônio Portes e Maria Apareicda Arruda (Orgs.), História da educação : ensino e pesquisa (pp. 11-26). Belo Horizonte : Autêntica.

\section{RESUMOS}

Ao conceito de gênero cabe a tarefa de problematizar os significados do que é ser mulher e homem nos distintos contextos históricos. O conceito de divisão sexual do trabalho possibilita examinar como essa divisão cria uma força de trabalho feminina, vista como mão de obra barata para certos tipos de afazeres, e como produz relações desiguais, hierarquizadas e assimétricas de exploração e opressão. Nesse sentido, propomos a articulação entre os conceitos de gênero e de divisão sexual do trabalho para a compreensão do uso do tempo no trabalho docente. Com base em pesquisa empírica de caráter qualitativo, desenvolvida com professoras e professores de uma escola de São Paulo entre 2006 e 2007, enfatizamos o caráter sexuado do trabalho docente, mas questionamos a dicotomia entre tempos de trabalho econômico maiores para os homens e tempos de trabalho para a reprodução social maiores para as mulheres, constatada na análise de outras profissões.

El concepto de género tiene la tarea de cuestionar el significado de ser mujer y ser hombre en diferentes contextos históricos. El concepto de división sexual del trabajo hace posible examinar cómo esta división crea una fuerza de trabajo femenina, considerada como mano de obra barata para ciertos tipos de tareas, y cómo se produce relaciones desiguales, jerárquicas y asimétricas de explotación y opresión. En consecuencia, proponemos una articulación entre los conceptos de género y de división sexual del trabajo para la comprensión del uso del tiempo $\mathrm{n}$ el trabajo docente. Sobre la base de investigación empírica cualitativa, desarrollada con maestras y maestros de una escuela en Sao Paulo entre 2006 y 2007, destacamos el carácter sexuado del trabajo docente, pero cuestionamos la dicotomía entre mayor cantidad de tiempo de trabajo 
económico para los hombres y entre mayor cantidad de tiempo de trabajo para la reproducción social para las mujeres, que se constatan en el análisis de otras profesiones.

Le concept de genre interroge le sens d'être une femme ou un homme dans des contextes historiques différents. Le concept de division sexuelle du travail permet d'analyser comment cette division crée une force de travail féminine bon marché pour certains types de tâches, et comment il en résulte inégalité, exploitation hiérarchique et asymétrique et oppression. Avec cette perspective, nous proposons une articulation entre les concepts de genre et de division sexuelle du travail afin de mieux saisir l'utilisation du temps dans le travail enseignant. En nous basant sur une recherche empirique qualitative, développée avec les enseignants (hommes et femmes) d'une école de São Paulo, entre 2006 et 2007, nous soulignons le caractère sexué de ce travail, mais nous questionnons aussi la dichotomie entre un temps de travail économique plus élevé pour les hommes et un temps de travail de reproduction sociale plus élevé pour les femmes, telle que rencontrée dans le cadre de l'analyse d'autres professions.

The concept of gender is responsible for questioning what it means to be a woman and a man in different historical contexts. The concept of sexual division of labor makes it possible to examine how this division creates a female labor force, considered as cheap manpower for certain types of tasks, and how it produces unequal, hierarchical and asymmetrical exploitation and oppression relations. Accordingly, we propose a link between the concepts of gender and sexual division of labor to understand the use of time in teaching. Based on qualitative empirical research, developed with male and female teachers from a school in São Paulo, between 2006 and 2007, we emphasized the gendered nature of the teaching activity, but we question the dichotomy between greater economic working time for men and greater working time for social reproduction for women, found in the analysis of other professions.

\section{ÍNDICE}

Keywords: gender relations, teaching, sexual division of labor, teaching working time Mots-clés: relations de genre, travail enseignant, division sexuelle du travail, temps de travail enseignant

Palabras claves: relaciones de género, trabajo docente, división sexual del trabajo, tiempos del trabajo docente

Palavras-chave: relações de gênero, trabalho docente, divisão sexual do trabalho, tempos de trabalho docente

\section{AUTORES}

\section{CAROLINA FARIA ALVARENGA}

Departamento de Educação - Universidade Federal de Lavras, Campus Universitário - Caixa Postal 3037

Lavras, Minas Gerais - Brasil

carol_alvarenga@ded.ufla.br

\section{CLÁUDIA PEREIRA VIANNA}

Faculdade de Educação - Universidade de São Paulo, Avenida da Universidade, 308 
São Paulo - Brasil

cpvianna@usp.br 